FACULTY OF ECONOMICS AND APPLIED ECONOMIC SCIENCES

CENTER FOR ECONOMIC STUDIES

ENERGY, TRANSPORT \& ENVIRONMENT

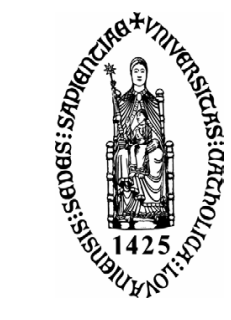

KATHOLIEKE UNIVERSITEIT

LEUVEN

WORKING PAPER SERIES

$n^{\circ}$ 2005-09

\title{
Asymmetric Duopoly in Space - what policies work?
}
F. Dunkerley (ETE - CES, KULEUVEN)

A. de Palma (Université de Cergy-Pontoise, ENPC and Member of Institut Universitaire de France, THEMA, 33) S. Proost (ETE - CES, KULEUVEN and CORE, UCL)

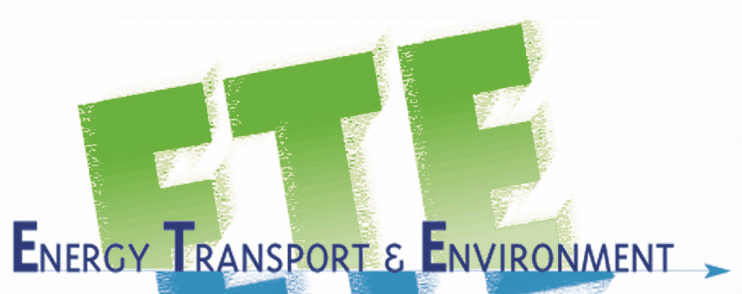

secretariat:

Isabelle Benoit

KULeuven-CES

Naamsestraat 69, B-3000 Leuven (Belgium)

tel: $\quad+32(0) 1632.66 .33$

fax: $\quad+32(0) 1632.69 .10$

e-mail: Isabelle.Benoit@econ.kuleuven.ac.be

http://www.kuleuven.be/ete 


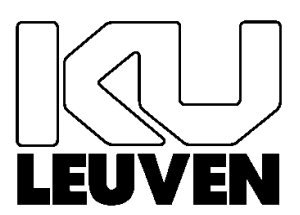

KATHOLIEKE

UNIVERSITEIT

LEUVEN

\title{
Asymmetric Duopoly in Space - what policies work?
}

\author{
Fay Dunkerley ${ }^{1}$, Andre de Palma ${ }^{2}$ and Stef Proost ${ }^{3}$
}

November 2005

\begin{abstract}
In this paper we study the problem of a city with access to two subcentres selling a differentiated product. The first subcentre has low free flow transport costs but is easily congested (near city centre, access by road). The second one has higher free flow transport costs but is less prone to congestion (ample public transport capacity, parking etc.). Both subcentres need to attract customers and employees by offering prices and wages that are sufficiently attractive to cover their fixed costs. In the absence of any government regulation, there will be an asymmetric duopoly game that can be solved for a Nash equilibrium in prices and wages offered by the two subcentres. This solution is typically characterised by excessive congestion for the nearby subcentre. We study the welfare effects of a number of stylised policies by setting up a general model and illustrating the model using competition between airports as an example.

The first stylised policy is to extend the congested road to subcentre 1 . This policy will not necessarily lead to less congestion as more customers will be attracted by the lower transport costs. The second policy option is to add congestion pricing (or parking pricing etc.) for the congested subcentre. This will decrease its profit margin and attract more customers. The third policy is acceptable for politicians: providing a direct subsidy to the remote subcentre, reducing its marginal costs. This policy will again ease the congestion problem for the nearby subcentre but will do this in a very costly way.
\end{abstract}

Keywords: duopoly, imperfect competition, congestion, general equilibrium, airport competition

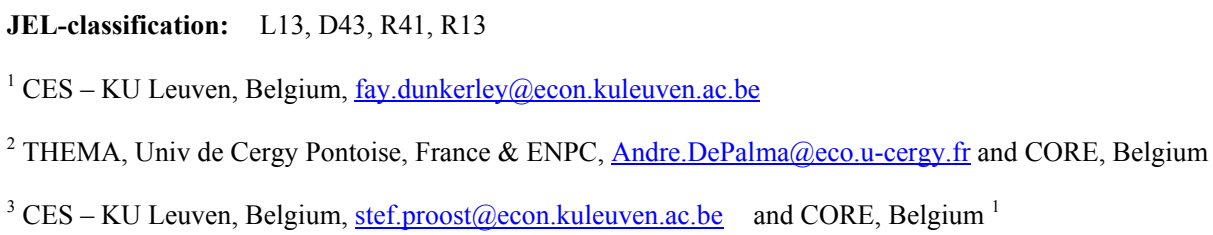




\section{Asymmetric Duopoly in Space - what policies work?}

\section{INTRODUCTION}

In this paper we study the problem of a city that has access to two facilities (e.g. shopping centres, airports) selling a differentiated product. The first subcentre has low transport costs but is easily congested (near city centre, access by road). The second one has higher transport costs but is less prone to congested access (ample public transport capacity, parking etc.). Both subcentres need to attract customers and employees by offering prices and wages that are sufficiently attractive to cover their fixed costs. The equilibrium is the outcome of the interplay between endogenous congestion and market forces. In the absence of any government regulation, there will be an asymmetric monopolistic competition game that can be solved for a Nash equilibrium in prices and wages offered by each of the two subcentres. This solution is typically characterised by excessive congestion for the nearby subcentre. We first analyse in detail the comparative statics for the duopoly set-up and then study the welfare effects of a number of stylised policies.

The first policy is to extend the road to the nearby facility, subcentre 1. Interestingly, this policy will not necessarily lead to less congestion as more customers will be attracted by the lower transport costs. This is close to the well known Braess paradox in transport economics (Braess 1969). In our paper we add product and labour differentiation and it will be the degrees of differentiation that will determine how successful the road extension strategy is. The second policy is to add congestion pricing (or parking pricing etc.) for the congested subcentre. This will decrease its profit margin (see de Palma and Proost, 2005) and attract more customers. The third policy is more acceptable for politicians: providing a direct subsidy to the remote subcentre, reducing its marginal costs. This policy will again ease the congestion problem for the nearby subcentre but will do this in a very costly way.

We apply our model to airports, using Brussels International Airport (Zaventem) and Charleroi -Brussels South (Charleroi) to illustrate the effect of the above policy options. Increasingly cities in Europe are served by two (or more) airports, which offer differentiated products in terms of quality and frequency of flights but also differ in their facilities and accessibility.

Our results show that, for the duopoly set-up, the difference in benefits accruing to residents who shop or work at the two subcentres is crucial in determining the difference in profits and market share. This is true both with and without congestion. When there is congestion, the difference in profits between the two firms increases if the road capacity of the intrinsically better firm increases. However, changes in the price and wage differences depend on trip frequency and consumer preferences for diversity. These results are borne out in our numerical airport application. Further, all three policies are shown to have attractive attributes.

The structure of the paper is as follows. In Section 2 we review the literature. The general theoretical framework of the model is described in Section 3 and the duopoly 
model is then considered in more detail in Section 4. The existing market equilibrium for the airport application is developed in Section 5 and the effects of our policy options are discussed. Section 6 concludes.

\section{LITERATURE}

A number of authors have addressed the issue of congestion in an oligopolistic setting. Scotchmer (1985) looks at price competition between congestible facilities in a symmetric setting when total demand is fixed. de Palma and Leruth (1989) present a two-stage duopoly game, in which the firms first choose capacities and then set prices for goods that are perfect substitutes. They consider both homogeneous consumers and consumers who differ in their willingness to pay to avoid congestion. Price competition between two firms offering perfect substitutes is also analysed by Van Dender (2005): in this case firms have congested access (for example to a port or airport) and there is additional non-duopoly traffic. de Palma and Proost (2005) consider price and wage competition between a number of firms supplying a differentiated product when the transport infrastructure may be congested. A bottleneck model is used and tolling examined. They present results for identical firms and transport infrastructure and for consumers who differ only in their intrinsic tastes. In this paper we build on de Palma and Proost (2005), adding asymmetries in firms' costs, infrastructure capacity and consumer preferences but limiting ourselves to a duopoly. In terms of pricing policies, de Palma and Lindsey (2000) also use a bottleneck model of congestion and compare the allocative efficiency gains of different pricing regimes on competing parallel roads. Ivaldi and Vibes (2004) model oligopolistic price competition between traditional and low cost airlines and rail competing on the same route using a game theoretic approach and consider the effect of a kerosene tax. There is no congestion in their model.

Another strand of the literature on spatial oligopoly with imperfect competition looks at location choice for firms and consumers. Fujita and Thisse (2002) provides an overview. Lambertini (1997), for example, investigates the use of tax or subsidies to directly affect firms' location in a horizontally differentiated duopoly without explicitly modifying their price behaviour. In our study, however, we consider the effect of policy on pricing behaviour of the existing duopoly firms at fixed locations.

The literature on airport and airline competition is also of interest for our model application. There are several econometric studies of airport choice which make use of data for three airports in the San Francisco Bay Area. Hess and Polak (2005) show that access time, fare and frequency of service have a significant influence on airport choice but this differed between types of travellers. Pels et al. (2003) look at access mode and airport choice for residents only and find access time to be the dominant explanatory factor. Basar and Bhat (2004) allow for the fact that travellers may not consider all available airports when choosing their departure airport but they also find access time to be important. The impact of low cost carriers on the industry has also been widely studied (see, for example, Barrett 2004 and Franke 2004). Pels and Rietveld (2004) also analyse price responses between low cost and traditional carriers using fare data for the Paris-London route. Fischer and Kamerschen (2003) use a conjectural variational approach to show that, for airlines in the US, entry of a low-cost carrier on a route reduces mark-up but not to a competitive level. Applying congestion tolling to cope 
with flight congestion at airports has also been studied (Brueckner 2002, Pels and Verhoef, 2004). Here we are concerned only with congested access to airports.

\section{THEORETICAL FRAMEWORK}

\subsection{Model Setting}

The model is based on de Palma and Proost (2005), in which a simple general equilibrium framework was developed to study imperfect competition in a city both with and without congestion. Although they concentrate their analysis on the symmetric situation, the basic model set-up also applies in the more general asymmetric case. A brief description of the model setting is therefore presented here together with the relevant equations for household preferences and firms' profits in an asymmetric oligopoly with congested transport infrastructure. A more detailed theoretical analysis of the duopoly model is presented in Section 4.

Residents live in a city centre and travel to one of two sub-centres to work and shop. Shopping and working decisions are made independently, so that trip chaining is excluded, and residents can only travel between the centre and each subcentre and not between subcentres (see Figure 1$)^{2}$. A homogeneous good is produced in the city centre and used as an intermediate input for the differentiated good, which is produced in the sub-centres. Thus, both firms and consumers incur travel costs. In this general equilibrium setting, the numéraire homogeneous good represents all production in the economy other than the differentiated good and all profits are returned to the households. The labour market is also considered separately and jobs in the differentiated industry are heterogeneous. Only one differentiated product variant is produced at each sub-centre by a single firm and each household will consume one unit of differentiated good and supply one unit of labour for its production. Hence, in the current formulation, demand for the differentiated good is inelastic and, if the labour market is assumed to be fully flexible, the product and labour markets will clear. All remaining labour $(\theta)$ and income is devoted to the homogeneous good and there is therefore no possibility of non-consumption or unemployment.

The total production possibilities of an economy with $N$ households and $n$ firms can then be expressed in terms of the following identity for labour supply and demand:

$$
(1+\theta) N=D+\sum_{i=1}^{N} c_{i} D_{i}+\sum_{i=1}^{n} F_{i}+\left(\alpha^{w}+\alpha^{d}+\alpha^{h}\right) \sum_{i=1}^{N} t_{i} D_{i}+\sum_{i=1}^{n} K_{i}+G,
$$

where $D\left(=\sum D_{i}\right)$ is the total demand for the differentiated good, $c_{i}$ is the marginal production cost of the intermediate input at subcentre $i, F_{i}$ is the fixed production cost for firm $i$ and transportation costs for commuting, shopping and supply of goods are

\footnotetext{
${ }^{2}$ While trip chaining can clearly be important in the decision process for many households, it significantly complicates the modelling process and is presented in a separate paper (de Palma, Dunkerley and Proost. 2005). Here we focus on households who, for example, do a weekly shop as a family, independent of work commitments or on an airport trip where customers and the workforce represent different sections of the population.
} 
given by $\left(\alpha^{w}+\alpha^{d}+\alpha^{h}\right) \sum_{i=1}^{N} t_{i} D_{i}{ }^{3}$. The $\alpha^{w}, \alpha^{d}$ and $\alpha^{h}$ denote trip frequencies and the $t_{i}$ travel times, which are exogenous when there is no congestion. Each sub-centre requires some road infrastructure $\left(K_{i}\right)$, which is paid for by a levy on firms and head-tax (T) on consumers. Finally, G denotes residual consumption of the homogeneous good.

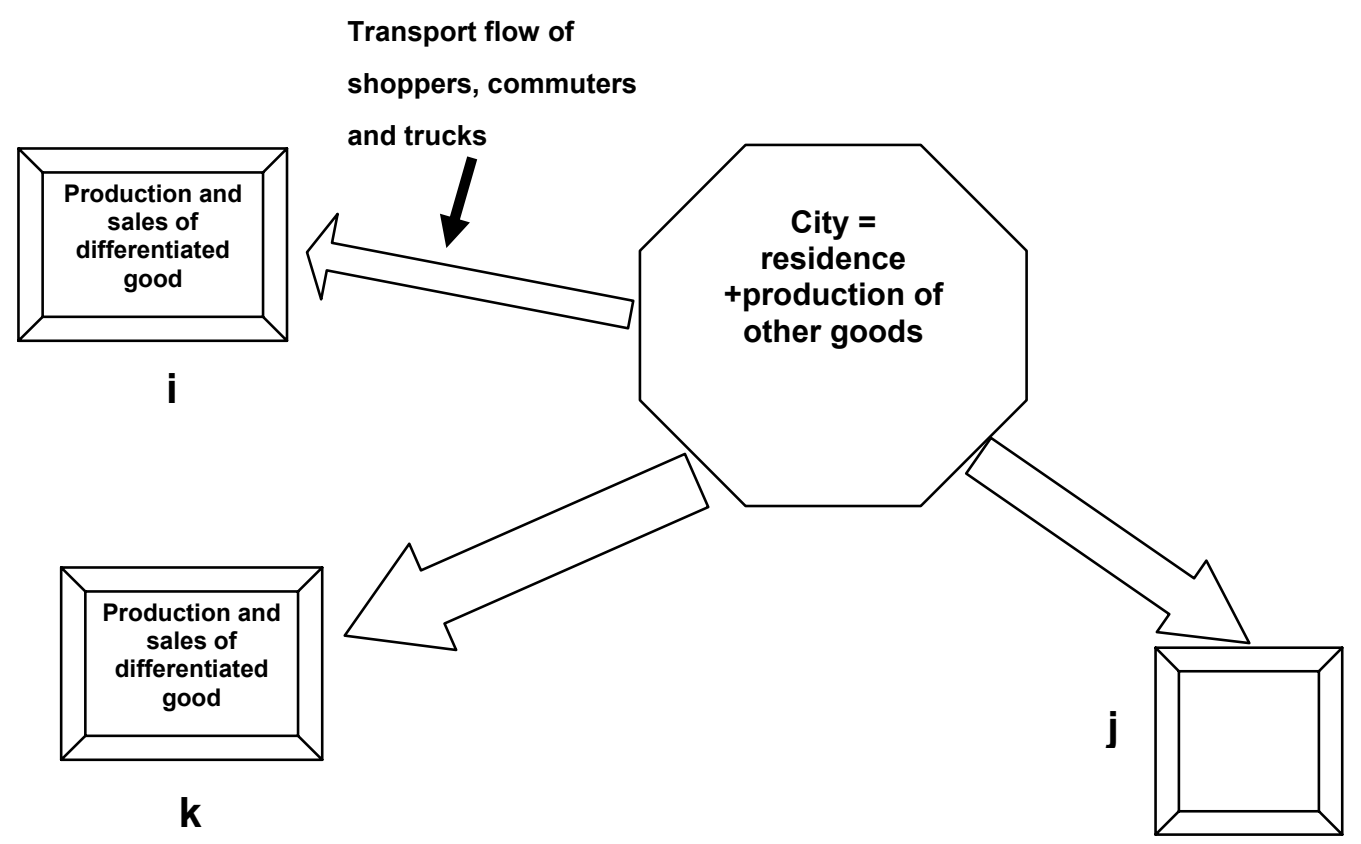

Figure 1 Schematic of city layout

\subsection{Congestion}

The main effect of congestion on the model is to make travel times endogenous. Instead of being constant, travel times increase with the number of road users, where the road users are customers, commuters and trucks delivering the intermediate input. de Palma and Proost 2005 assume that roads have a fixed capacity and that a bottleneck develops if the activity on a road exceeds its capacity. They use the bottleneck model developed by Arnott, de Palma and Lindsey 1993, where road users choose their trip timing (with no congestion pricing). In the simplest case, where all agents have the same desired arrival times and the same valuation of time, we can define the endogenous travel time for the asymmetric model as

$$
t_{i}=t_{i}^{o}+\delta \frac{N}{s_{i}} \alpha P_{i}^{w}
$$

where $\alpha=\alpha^{d}+\alpha^{w}+\kappa \alpha^{h}$ and $\kappa$ ensures that one truck trip has the same congestion effect as $\kappa$ shopping or commuting trips. In the absence of congestion $t_{i}^{o}$ is the transport time from the centre to sub-centre $i$ and $s_{i}$ is the corresponding road capacity.

\footnotetext{
${ }^{3}$ Note that because wages and prices for the homogeneous good have been normalised to one, the value of time is also one.
} 
From (2) it can be seen that roads are free of congestion in the limit of infinite bottleneck capacity. ${ }^{4}$ The coefficient $\delta$ translates waiting time and schedule delays into equivalent costs.

\subsection{Household Preferences}

Household utility is represented by a linear function of the utility obtained from consumption of the differentiated and homogeneous goods and the disutility of supplying labour to the production of these goods. Using the household budget equation to substitute for consumption of the homogeneous good, an indirect conditional utility function can be derived to express household preferences. In this case the utility function represents the preferences of a household that buys differentiated good $k$ and supplies labour to sub-centre $i$ :

$$
U_{i k}=\tilde{h}_{k}-p_{k}-\alpha^{d} t_{k}+w_{i}-\tilde{\beta}_{i}-\alpha^{w} t_{i}+\theta(1-\beta)+\frac{1}{N} \sum_{l=1}^{n} \pi_{l}-T, \quad i, k=1 \ldots n .
$$

Each of the $\mathrm{N}$ households is paid a wage, $w_{i}$, for working at subcentre $i$ and buys one unit of variant $k$ at price, $p_{k}$. Both prices and wages will be determined by the model. In the following we will use household and consumer interchangeably as it is easier to consider the household as a single worker or customer. Thus, the consumer's commuting and shopping travel costs are given by $\alpha^{w} t_{i}$ and $\alpha^{d} t_{i}$ respectively, where, from (2), $t_{i}$ is endogenous. The utility of consumption of differentiated product variant $k$ is given by an intrinsic quality component $h_{k}$ and a stochastic component $\mu^{d} \varepsilon_{k}$ :

$$
\tilde{h}_{k}=h_{k}+\mu^{d} \varepsilon_{k}
$$

and the disutility of labour at subcentre $i$ is similarly given by the following two components

$$
\tilde{\beta}_{i}=\beta_{i}-\mu^{w} \varepsilon_{i} .
$$

Hence, all households will value the quality of the product variant manufactured at a particular subcentre in the same way and will experience the same disinclination to work at a given subcentre; in both cases possibly assigning different values to different subcentres. However, the households will still vary in their tastes: $\varepsilon_{i}$ and $\varepsilon_{k}$ are random variables which represent the intrinsic heterogeneity of consumer tastes and it is assumed that they are independently, identically distributed according to the double exponential distribution. The (non-negative) parameters $\mu^{w}$ and $\mu^{d}$ determine the degree of heterogeneity of preferences.

The remaining terms in (3) represent a household's utility from production of the homogeneous good, share of the profits and the head-tax $(\mathrm{T})$. These are the same for all consumers.

\footnotetext{
${ }^{4}$ The non-congestion case is actually modelled separately using exogenous travel times; $s$ is not used.
} 
When a household chooses where to work, this decision is independent of its shopping decision and vice versa since we rule out trip chaining. Substituting from (4) and (5) in (3), we obtain

$$
U_{i \mid k}=\Omega_{k}+w_{i}-\beta_{i}-\alpha^{w} t_{i}+\mu^{w} \varepsilon_{i},
$$

where $\Omega_{k}=\theta(1-\beta)+\frac{1}{N} \sum_{l} \pi_{l}-T+h_{k}-p_{k}-\alpha^{d} t_{k}+\mu^{d} \varepsilon_{k}$ is assumed fixed for the choice of employment location. The probability that a consumer chooses to commute to sub-centre $i$ of the $n$ possible sub-centres is then $P_{i}^{w}=\operatorname{Pr} o b\left\{U_{i \mid k} \geq U_{j \mid k} \forall j=1, \ldots, n\right\}$. This can be written as a logit type probability

$$
P_{i}^{w}=\frac{\exp \left(\frac{w_{i}-\beta_{i}-\alpha^{w} t_{i}}{\mu^{w}}\right)}{\sum_{j} \exp \left(\frac{w_{j}-\beta_{j}-\alpha^{w} t_{j}}{\mu^{w}}\right)}, i=1 \ldots n,
$$

which is independent of $k$. For the household choice of shopping location, we obtain

$$
U_{k \mid i}=\Omega_{i}+h_{k}-p_{k}-\alpha^{d} t_{k}+\mu^{d} \varepsilon_{k},
$$

where $\Omega_{i}=\theta(1-\beta)+\frac{1}{N} \sum_{l} \pi_{l}-T+w_{i}-\beta_{i}-\alpha^{w} t_{i}+\mu^{w} \varepsilon_{i}$ is assumed constant for shopping decisions, and a similar expression for the probability is derived:

$$
P_{k}^{d}=\frac{\exp \left(\frac{h_{k}-p_{k}-\alpha^{d} t_{k}}{\mu^{d}}\right)}{\sum_{j} \exp \left(\frac{h_{j}-p_{j}-\alpha^{d} t_{j}}{\mu^{d}}\right)}, k=1 \ldots n .
$$

Since travel times are endogenous (2), (6) and (7) are implicit equations in $P_{i}^{w}$ and $P_{k}^{d}$. Even for the duopoly case, these equations cannot be solved analytically, since $t_{k}$ is endogenous, and a numerical solution is required for each value of $p$ and $w$.

Using the assumptions of inelastic demand for the differentiated good and fixed labour input for the differentiated good, a market clearing condition also applies at each subcentre:

$$
P_{i}^{w}=P_{i}^{d}
$$

\subsection{Profits of firms}

There are $n$ firms, each located at one of the subcentres. The profit of firm $i$ is

$$
\pi_{i}(w, p)=\left(p_{i}-w_{i}-c_{i}-\alpha^{h} t\right) D_{i}-\left(F_{i}+S_{i}\right),
$$


where $c_{i}+\alpha^{h} t_{i}$ is the marginal cost of the intermediate input, $F_{i}$ is the fixed production cost and $S_{i}$ is the government levy to pay for public infrastructure. The inelastic demand condition gives us $\sum_{i=1}^{n} D_{i}=N$ and from (8), we obtain demand $D_{i}=N P_{i}^{w}=N P_{i}^{d}$.

Each firm selects prices and wages to maximise his profits, given that his competitors do the same. Thus we look for a non-cooperative Nash equilibrium in these variables.

\subsection{Equilibrium}

The strategic variables of firm $i$ are $w_{i}$ and $p_{i}$. From the market clearing condition (8), substituting from (6) and (7), it is clear that the choice of $w_{i}$ determines the choice of $p_{i}$ (and vice versa), since all other prices and wages are taken as given. Thus, we can rewrite the profit equation (9) as

$$
\pi_{i}\left[w_{i}\right]=\left(p_{i}\left[w_{i}\right]-w_{i}-c_{i}-\alpha^{h} t_{i}\right) N P_{i}^{w}\left[w_{i}\right]-\left(F_{i}+S_{i}\right) .
$$

Thus, taking $w_{i}$ as our only strategic variable, the best response of firm $i$ is given by

$$
\frac{d \pi_{i}}{d w_{i}}=\left[\frac{d p_{i}}{d w_{i}}-1\right] N P_{i}^{w}+\left[p_{i}-w_{i}-c_{i}-\alpha^{h} t_{i}^{o}-2 \Lambda_{i}^{h} P_{i}^{w}\right] N \frac{d P_{i}^{w}}{d w_{i}}=0,
$$

where

$$
\begin{gathered}
\frac{d P_{i}^{w}}{d w_{i}}=\frac{P_{i}^{w}\left(1-P_{i}^{w}\right)}{\left[\mu^{w}+\Lambda_{i}{ }^{w} P_{i}^{w}\left(1-P_{i}^{w}\right)\right]} \\
\frac{d p_{i}}{d w_{i}}=-\frac{\left[\mu^{d}+\Lambda_{i}{ }^{d} P_{i}^{d}\left(1-P_{i}^{d}\right)\right]}{\left[\mu^{w}+\Lambda_{i}{ }^{w} P_{i}^{w}\left(1-P_{i}^{w}\right)\right]} \text { and } \Lambda_{i}^{h}=\frac{\alpha \alpha^{h} N \delta}{s_{i}} .
\end{gathered}
$$

Simplifying (11) and using the market clearing condition (8) leads to

$$
\frac{N P_{i}^{w}\left(1-P_{i}^{w}\right)}{\left[\mu^{w}+\Lambda_{i}{ }^{w} P_{i}^{w}\left(1-P_{i}^{w}\right)\right]}\left[\frac{\left(\mu^{d}+\mu^{w}\right)}{1-P_{i}^{w}}-\left(p_{i}-w_{i}-c_{i}-\alpha^{h} t_{i}^{o}\right)+\Lambda_{i}^{h} P_{i}^{w}+\frac{\delta N \hat{\alpha}^{2}}{s_{i}} P_{i}^{w}\right]=0
$$

and hence the candidate Nash equilibrium in prices and wages is given by

$$
p_{i}=\frac{\left(\mu^{d}+\mu^{w}\right)}{1-P_{i}^{w}}+w_{i}+c_{i}+\alpha^{h} t_{i}^{o}+\Lambda_{i}^{h} P_{i}^{w}+\frac{\delta N \hat{\alpha}^{2}}{s_{i}} P_{i}^{w} .
$$

This wage-price equilibrium cannot be solved analytically, except for the symmetric solution. In addition, $P_{i}^{w}$, given by (6), and $P_{i}^{d}$ given by relation (7) are now endogenous, which again requires a numerical approach. For the numerical solution we have to calculate both $p_{i}$ and $w_{i}$. Thus we have $2 n$ unknowns and only $n$ equations from the price equilibrium (13). However, the market clearing conditions, (8), provide $n$ further relations between $p_{i}$ and $w_{i}$. Unfortunately, these do not allow us to fully specify the problem, as, for the logit model, the $n t h$ relation, $P_{n}{ }^{w}=P_{n}{ }^{d}$, can be determined from the other $n-1$ market clearing conditions; we then have $2 n$ unknowns and $2 n-1$ 
equations. Fixing the wage (or one price) of one firm leaves $P_{i}^{w}$ and $P_{i}^{d}$ unchanged but allows us to uniquely specify $p_{i}$ and $w_{i}$ for all $i$.

Congestion has the following effects. Firstly, it makes delivery of the intermediate good more expensive. Secondly, there are time costs (schedule delay costs), since the traffic is not able to travel at the free-flow speed $\left(t^{o}{ }_{i}\right)$ even if perfect congestion pricing can be imposed. In addition, if congestion is imperfectly priced, there are queuing costs. These two costs are reflected in the $\delta N \hat{\alpha}^{2} P^{w}{ }_{i} / s_{i}$ term in (13). Further, congestion makes the effective demand function for the subcentres' products steeper as any price decrease will initially attract more customers. However, these customers will themselves increase travel time so that, in the end, the net increase in the number of customers is somewhat lower. The increased price in turn leads to greater profits. A similar argument also applies to wages. If firms reduce prices and increase market share, they will need to attract more workers but the commuting workers will add to congestion.

\subsection{Welfare Analysis}

In addition to effects on price, profit and market share, we are interested in the welfare implications of the asymmetric model. Welfare is defined as the sum of consumer and producer surpluses and, for our model, welfare per household can be derived from $W=\max E\left[U_{i k}\right]$, since profits are equally distributed among households (Anderson et al. 1992). Using the definition of utility (3) and substituting the random variables from (4) and (5) we obtain

$$
U_{i k}=h_{k}-p_{k}-\alpha^{d} t_{k}+\mu^{d} \varepsilon_{k}+w_{i}-\beta_{i}-\alpha^{w} t_{i}-\mu^{w} \varepsilon_{i}+\theta(1-\beta)+\frac{1}{N} \sum_{l} \pi_{l}-T .
$$

Then, because of the independence of the labour and consumption decisions in (15), we can write

$$
W=\Psi+\max _{i} E\left[w_{i}-\beta_{i}-\alpha^{w} t_{i}+\mu^{w} \varepsilon_{i}\right]+\max _{k} E\left[h_{k}-p_{k}-\alpha^{d} t_{k}+\mu^{d} \varepsilon_{k}\right],
$$

where $\Psi=\theta(1-\beta)+\frac{\sum_{1}^{n} \pi_{l}}{N}-T$. Given that the error terms are double exponentially distributed, after some further manipulation (see for example Anderson et al. 1992), the welfare formulation for the one day economy can be expressed as

$$
W=\Psi+\mu^{w} \ln \left[\sum_{j} \exp \left(\frac{\left(w_{j}-\beta_{j}-\alpha^{w} t_{j}\right)}{\mu^{w}}\right)\right]+\mu^{d} \ln \left[\sum_{j} \exp \left(\frac{h_{j}-p_{j}-\alpha^{d} t_{j}}{\mu^{d}}\right)\right],
$$

which can be further simplified using the market clearing condition, which implies a linear relation between prices differences and wages difference.

This measure of welfare in the short-run uses the equilibrium prices, wages and travel costs calculated by the model, which enter the welfare formulation via the exponential terms and the profit. When we add fully time differentiated congestion pricing in this bottleneck model, half of the sum of schedule delay and queuing costs are converted 
into toll revenue. This toll revenue corresponds to the direct welfare gain (in terms of saved transport costs) of tolling. There can be indirect welfare gains or losses via changes in profit margins that can change, in the long term, the number of subcentres. Indeed, congestion may lead to over-entry in the longer term, since firms are able to make larger profits in the absence of road pricing (see de Palma and Proost 2005).

\section{DUOPOLY MODEL}

In the duopoly case, the $2 n-1$ equations,(6), (7) and (13), with $2 n$ unknowns (prices and wages) problem, can be simplified. The expression (6) for $P_{i}^{w}$ reduces to

$$
P_{1}^{w}=\left[1+\exp \left(\frac{X^{w}}{\mu^{w}}\right)\right]^{-1},
$$

where $X^{w}=w_{2}-w_{1}+\beta_{1}-\beta_{2}-\alpha^{w}\left(t_{2}-t_{1}\right)$. Clearly $P_{2}{ }^{w}=1-P_{1}^{w}$.Moreover, we have from (7)

$$
P_{1}^{d}=\left[1+\exp \left(\frac{X^{d}}{\mu^{d}}\right)\right]^{-1},
$$

where $X^{d}=p_{1}-p_{2}+h_{2}-h_{1}-\alpha^{d}\left(t_{2}-t_{1}\right)$. Note that $X^{w}$ and $X^{d}$ represent respectively the difference in utility experienced by a consumer who chooses to work or shop at the two firms.

We know from market clearing that $P_{1}^{w}=P_{1}^{d}$. The above equations thus imply that there is an equality between net price and net wage difference, weighted by the degree of heterogeneity in consumer preferences

$$
X^{w} / \mu^{w}=X^{d} / \mu^{d} .
$$

Using the Nash equilibrium first order condition (13) to compute the price differences, and using the relation between the price difference and the wage difference necessary for market clearing, (19), we can obtain unique implicit equation in the price difference, which has a unique solution.

In general the transport time component of $X^{w}$ and $X^{d}$ is endogenous and varies with congestion (see (2)). This is the case we are most interested in for real world modelling applications. However, the solution is less tractable as price and wage differences are related in a non-linear way. We therefore also consider the model without congestion in order to gain some useful insights. In the following analysis we first present the implicit equation in price difference without congestion and then consider the effects of adding congestion. A full derivation can be found in Appendix 2.

\subsection{Comparative Statics without Congestion}

First defining $\Delta h=h_{2}-h_{1}, \Delta \beta=\beta_{2}-\beta_{1}, \Delta c=c_{2}-c_{1}$ and $\Delta t^{o}=t^{o}{ }_{2}-t^{o}{ }_{1}$, we can express the implicit price difference equation without congestion as (see Appendix 2, (8)) 


$$
X^{d}=-2 \mu^{d} \sinh \left(\frac{X^{d}}{\mu^{d}}\right)+\left(\frac{\mu^{d}}{\mu^{d}+\mu^{w}}\right) B,
$$

where $B \equiv\left[\Delta h-\Delta \beta-\Delta c-\hat{\alpha} \Delta t^{0}\right]$ and $\hat{\alpha} \equiv \alpha^{d}+\alpha^{w}+\alpha^{h}$. The $B$ is constant and depends only on the exogenous parameters. It represents the difference in benefits accruing to residents who shop or work at the two subcentres and can be seen as a rank parameter to determine the optimal order for long term entry (from a welfare point of view) when there is no congestion. Further, defining $\Delta p=p_{2}-p_{1}$ and $\Delta w=w_{2}-w_{1}$, we have $X^{d}=-\Delta p+\Delta h-\alpha^{d} \Delta t^{o}$, which represents the intrinsic difference in consumers' appreciation of the two products. Note, in this case, the travel time is fixed exogenously as there is no congestion.

We can also express the difference in profit between the two firms as

$$
\frac{\Delta \pi}{N}=2\left(\mu^{d}+\mu^{w}\right) \sinh \left(\frac{X^{d}}{\mu^{d}}\right)-\frac{\Delta(F+S)}{N},
$$

where $\Delta \pi=\pi_{2}-\pi_{1}$ and $\Delta(F+S)$ represents the difference in fixed costs between the two firms.

The "rank" $B$ is a crucial parameter in determining the effect of differences in the characteristics of the two competing firms. Consider first the case when $B \equiv\left[\Delta h-\Delta \beta-\Delta c-\hat{\alpha} \Delta t^{0}\right]=0$. This situation not only arises when the firms are identical but also when the combination of quality and cost parameters of the two firms are such that they are ranked in the same way. The only solution to (20) is then $\Delta p=\Delta h-\alpha^{d} \Delta t^{0}$, since $X^{d}=0$ and, from (19), we have $\Delta w=\Delta \beta-\alpha^{w} \Delta t^{0}$. Profits and market share are also equal. This result corresponds to the first column in Table 1.

When the gross benefits accruing to residents that work or shop at subcentre 2 are greater than those accruing to residents who patronise subcentre $1, B$ is positive $e^{5}$ In this case, $X^{w}$ and $X^{d}$ are also positive so the conditions on the price and wage differences become $\Delta p<\Delta h-\alpha^{d} \Delta t^{0}$ and $\Delta w>\Delta \beta-\alpha^{w} \Delta t^{0}$. The intuition is that, in this Nash equilibrium, in order to maximise profits, the firm with an absolute advantage has an interest in absorbing part of this absolute advantage, by limiting its price increase, for the purpose of increasing market share and ultimately profits. It can further be shown by differentiating $(20)^{6}$ that $\Delta p$ is an increasing function of $\Delta h, \Delta \beta$ and $\Delta c$, while $\Delta w$ increases with $\Delta \beta$ and $\Delta h$ but decreases with $\Delta c$. The intuition for $\Delta p$ being an increasing function of $\Delta \beta$ is less obvious: an increase in the disutility of labour (increase in $\beta_{2}$ ) requires an increase in $w_{2}$ to attract sufficient labour and a reduction in sales achieved by increasing $p_{2}$. When we start with $B=0$ so that both subcentres have the same intrinsic benefits, a small decrease in the access time for subcentre 2 ( decrease in $\Delta t^{\circ}$ ) means $B>0$ and this leads, ceteris paribus, to an increase in $\Delta p$ and

\footnotetext{
${ }^{5}$ For $\mathrm{B}<0$, we just reverse the firms.

${ }^{6}$ Also requires differentiation of the equivalent expression for $\mathrm{X}^{\mathrm{w}}$
} 
$\Delta w$, where the size of the increase is determined by the shopping and commuting frequency $\hat{\alpha}$.

Prices, wages and profits also depend on the degree of consumer heterogeneity with respect to working and shopping preferences, represented by parameters $\mu^{w}$ and $\mu^{d}$. Price differences generally decrease with $\mu^{d}$ and increase with $\mu^{w}$, whereas wage differences decrease with $\mu^{d}$ and increase with $\mu^{w}$. The difference in profits and the difference in market share are symmetric functions of $\mu^{d}$ and $\mu^{w}$, which mainly decrease as $\mu^{d}$ or $\mu^{w}$ increases, although this depends on the magnitude of the rank $B$ and the consumer heterogeneity parameters ${ }^{7}$. In general stronger consumer preferences for diversity mean that firm 2 cannot make the most of its intrinsic advantage and its profits and sales consequently suffer.

\begin{tabular}{|c|c|c|c|c|c|c|c|c|}
\hline & $\begin{array}{l}B=0 \\
\text { (same rank) }\end{array}$ & $\begin{array}{l}B>0 \\
(2 \quad \text { intrinsically } \\
\text { better than } 1)\end{array}$ & $\begin{array}{l}\Delta h \\
h_{2^{-}} \\
h_{1}\end{array}$ & $\begin{array}{l}\Delta \beta \\
\beta_{2^{-}} \beta_{1}\end{array}$ & $\begin{array}{l}\Delta c \\
c_{2}-c_{1}\end{array}$ & $\begin{array}{l}\Delta t^{o} \\
t_{2}^{o}-t_{1}^{o}\end{array}$ & $\mu^{d}$ & $\mu^{w}$ \\
\hline $\begin{array}{l}\Delta \pi=\pi_{2^{-}} \\
\pi_{1}\end{array}$ & 0 & $\uparrow$ & $\uparrow$ & $\downarrow$ & $\downarrow$ & $\downarrow$ & $\downarrow$ & $\downarrow$ \\
\hline $\begin{array}{c}\Delta \text { market } \\
\text { share }= \\
P_{2}-P_{1}\end{array}$ & 0 & $\uparrow$ & $\uparrow$ & $\downarrow$ & $\downarrow$ & $\downarrow$ & $\downarrow$ & $\downarrow$ \\
\hline $\begin{array}{l}\Delta p=p_{2^{-}} \\
p_{1}\end{array}$ & $=\Delta h-\alpha^{d} \Delta t^{0}$ & $<\Delta h-\alpha^{d} \Delta t^{0}$ & $\uparrow$ & $\uparrow$ & $\uparrow$ & $\uparrow$ & $\downarrow$ & $\uparrow$ \\
\hline $\begin{array}{l}\Delta w=w_{2-} \\
w_{1}\end{array}$ & $=\Delta \beta-\alpha^{w} \Delta t^{0}$ & $>\Delta \beta-\alpha^{w} \Delta t^{0}$ & $\uparrow$ & $\uparrow$ & $\downarrow$ & $\uparrow$ & $\downarrow$ & $\uparrow$ \\
\hline
\end{tabular}

Table 1 Comparative statics without congestion

\subsection{Comparative statics with congestion}

When congestion is added to the model, congestion related terms appear in the price, wage and profit difference equations. Further, the time components of $X^{w}$ and $X^{d}$ are no longer exogenous and explicitly include congestion effects. These congestion terms depend on trip frequency and road capacity. The impact of congestion will be small if trip frequency is low or there is little congestion (ample road capacity $s_{i}$ ) so that the congestion part $\left(\delta N s_{i}^{-1} \alpha P_{i}^{w}\right)$ of (2) $\left(t_{i}=t_{i}^{o}+\delta N s_{i}^{-1} \alpha P_{i}^{w}\right)$ is small.

We first consider the case when there is congestion but road capacity is the same for both firms $\left(s_{1}=s_{2}=s\right)$. Defining $\Delta P^{d}=\frac{P_{2}^{d}}{s_{2}}-\frac{P_{1}^{d}}{s_{1}}$, we find that

\footnotetext{
${ }^{7}$ See Appendix 2.1 for the conditions under which these results apply.
} 


$$
\Delta P^{d}=\frac{1}{S}\left(\exp \left(\frac{X^{d}}{\mu^{d}}\right)-1\right)\left(1+\exp \left(\frac{X^{d}}{\mu^{d}}\right)\right)^{-1},
$$

where now $X^{d}=-\Delta p+\Delta h-\alpha^{d} \Delta t^{o}-\alpha^{d} \alpha \delta N \Delta P^{d}$, where the last term represents the endogenous congestion part. The implicit price difference equation with congestion becomes

$$
\frac{X^{d}}{\mu^{d}}=-2 \sinh \left(\frac{X^{d}}{\mu^{d}}\right)-\left(\frac{2 \hat{\alpha}^{2} \delta N}{\mu^{d}+\mu^{w}}\right) \Delta P^{d}+\left(\frac{B}{\mu^{d}+\mu^{w}}\right) .
$$

A corresponding expression can be derived for $X^{w}=\Delta w-\Delta \beta-\alpha^{w} \Delta t^{o}-\alpha^{w} \alpha \delta N \Delta P^{w}$.

The difference in profits now takes the form

$$
\frac{\Delta \pi}{N}=B-\frac{\mu^{d}+\mu^{w}}{\mu^{d}} X^{d}-\delta N \hat{\alpha}^{2} \Delta P^{d}-\frac{\Delta(F+S)}{N} .
$$

It can be shown by differentiating (23) and (24) (see Appendix 2.2) that the difference in utility for consumers who shop $\left(X^{d}\right)$ or work $\left(X^{w}\right)$ at the two subcentres increases with road capacity for $X^{d}>0$. The intuition is that when $X^{d}>0$, there is an intrinsic advantage to shop at subcentre 2 . When road capacity on the two routes is increased, subcentre 2 has an incentive to attract more customers by lowering its price, as the extra customers are now less discouraged by the higher congestion this creates. This means a higher difference in utility but also a higher difference in profits.

With regard to differences in prices, for $X^{d}>0, \Delta p$ increases with road capacity if $\frac{3}{2} \frac{\alpha^{d}}{\hat{\alpha}}>\left(\frac{\mu^{d}}{\mu^{d}+\mu^{w}}\right)$. This inequality condition implies that price difference increases with road capacity when the trip frequency for shopping relative to total trip frequency is more important than consumer shopping diversity preferences relative to their overall preferences for diversity. For wage differences, $\Delta w$ increases with road capacity if $\frac{3}{2} \frac{\alpha^{w}}{\hat{\alpha}}<\left(\frac{\mu^{w}}{\mu^{d}+\mu^{w}}\right):$ this inequality compares the relative importance of commuting trip frequency and workplace preferences. In general, the above conditions mean that when price differences increase with road capacity, wage differences decrease. If the utility gained from working and shopping at firm 2 is sufficiently higher than from firm 1, an increase in road capacity allows firm 2 to raise its product price and lower its wage, thereby increasing profits. The market share of firm 2 will also be larger. Note that this analysis is only concerned with the relative performance of the two firms. It is clear from the Nash equilibrium in prices and wages (13) that the mark-up for both firms is greater with congestion than without.

When road congestion for the two firms in the duopoly model differs then

$$
\Delta P^{d}=\frac{1}{s_{2}}\left(\exp \left(\frac{X^{d}}{\mu^{d}}\right)-\frac{s_{2}}{s_{1}}\right)\left(1+\exp \left(\frac{X^{d}}{\mu^{d}}\right)\right)^{-1}
$$

and 


$$
\Delta \pi=2 N\left(\mu^{d}+\mu^{w}\right) \sinh \left(\frac{X^{d}}{\mu^{d}}\right)+\delta N^{2} \hat{\alpha}^{2}\left[\frac{\left(P_{2}^{d}\right)^{2}}{s_{2}}-\frac{\left(P_{1}^{d}\right)^{2}}{s_{1}}\right]-\Delta(F+S) .
$$

The implicit price equation is unchanged from (23), albeit with a different $\Delta P^{d}$. It can be shown by differentiation (Appendix 2.3) that $\partial X^{d} / \partial s_{1}<0$ and $\partial X^{d} / \partial s_{2}>0$. The effect of congestion on the difference in profits, prices and wages depends on the relative magnitude of the capacities $\left(s_{1}\right.$ and $\left.s_{2}\right)$ and the model input parameters. The difference in profits increase with $s_{2}$ and decrease with $s_{1}$ when $X^{d}>0$, which corresponds to the utility gained from shopping at subcentre 2 being greater than that from subcentre $1^{8}$.

The condition for the difference in prices to increase with $s_{2}$ and decrease with $s_{1}$ when $X^{d}>0$ is $\frac{3}{2} \frac{\alpha^{d}}{\hat{\alpha}}>\left(\frac{\mu^{d}}{\mu^{d}+\mu^{w}}\right)$, while the condition for the difference in wages is $\frac{3}{2} \frac{\alpha^{w}}{\hat{\alpha}}<\left(\frac{\mu^{w}}{\mu^{d}+\mu^{w}}\right)$. Hence, as in the previous discussion for identical road capacities, in general when price differences increase, wage differences decrease, dependent on the relative importance of trip frequency and consumer preference for shopping and working respectively.

It can also be shown that the comparative statics results from the previous section for price, wage and profit differences as a function of the difference in exogenous input parameters $\left(\Delta h, \Delta \beta, \Delta c, \Delta t^{o}\right.$ and $B$ ) also hold when both firms are subject to congestion. The specific conditions for $\Delta t^{o}$ are of course different but still depend on the trip frequency and consumer heterogeneity. Obviously only a numerical model allows us to fully appreciate the relative importance of the different factors. In the next section we apply the model to a real world case.

\section{APPLICATION TO AIRPORT COMPETITION}

We apply the basic duopoly model to the case of airports offering a package flight and parking facilities as their differentiated product. Increasingly cities in Europe are served by two (or more) airports, which offer differentiated products in terms of quality and frequency of flights but also differ in their facilities and accessibility. Examples include London, which is served by Heathrow, Gatwick, Stansted, Luton and the City airport, Rome (Ciampino and Fiumincino) and Stockholm (Arlanda and Bromma). In this paper we wish to focus on the situation where one airport is located close to the city, offering high quality facilities and frequent flights, while the second is more remote and offers a 'no-frills' service. Brussels, Hamburg and Venice can be considered to fall into this category. In particular we concentrate on the case of Brussels International Airport (Zaventem) and Charleroi-Brussels South Airport (Charleroi), which are located $13 \mathrm{~km}$ and $46 \mathrm{~km}$ from the centre of Brussels respectively. The model structure is shown in

\footnotetext{
${ }^{8}$ However, it is possible that profits will still follow this trend for some vales of $X^{d}<0$.
} 
Figure 2. We then consider the effect of a number of policy options on prices and wages, market share and degree of transport congestion. Clearly a number of simplifying assumptions need to be made in order to fit the model to this application. However, given this limitation, it is still possible to generate some interesting results from the different policy scenarios.

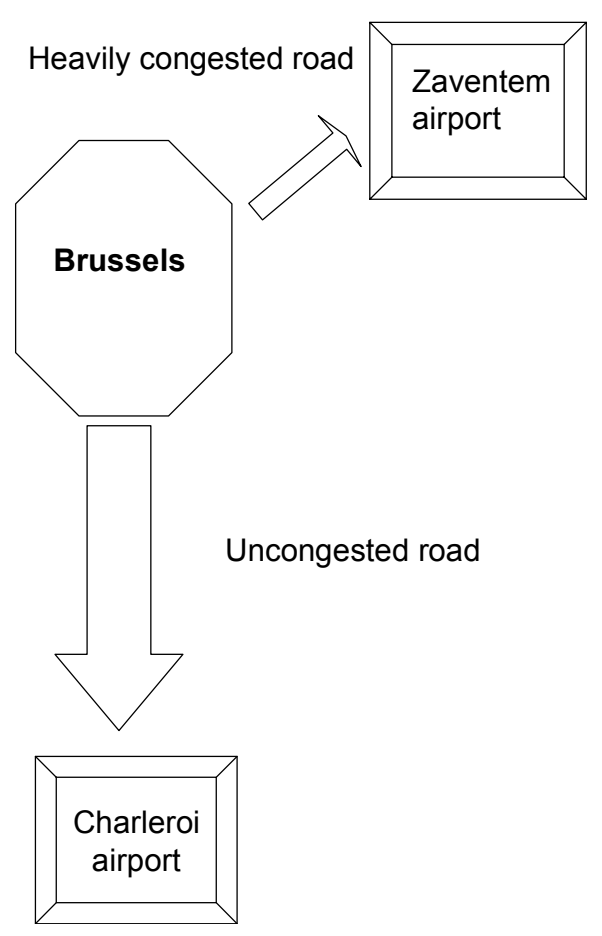

Figure 2 Duopoly structure - airport example

Zaventem airport offers frequent flights to a large number of destinations by a range of airlines. It has good facilities including, for example, many shops, cafes and bars. With annual passenger numbers of 15.5 million and car parking for 9000 vehicles, there is some road congestion and queuing for parking. Charleroi, on the other hand is a base for a small number of low cost airlines, flying infrequently to a limited number of destinations. It has limited amenities: only one shop and café. However, with two million passengers per year and parking for over 2000, its road infrastructure is much less congested. We assume in both cases that the bottleneck for road access occurs at the airport entrance. Both airports have public transport connections but we neglect these for the purposes of our comparison. ${ }^{9}$

In this simple application both airports offer flights to the same single destination with parking as their differentiated product (hereafter passenger-flight). There are many differentiated destinations offered by the two airports. For the sake of simplicity, we took one common destination, Dublin, to be representative of prices to all destinations. There is no competition between carriers at each airport as, in each case, only one airline offers flights to this destination. Further, our city has a population of 8 million, which is considered to be the approximate number of potential airport customers in

\footnotetext{
${ }^{9}$ In fact Charleroi has bus connections from each flight to the centre of Brussels and there are at least 3 trains per hour between Zaventem and central Brussels for most of the day.
} 
Belgium. This city is then assumed to be the only source of passengers and workers at the airports. Clearly this implies that everyone is travelling to the airports along the same route. Although this is not realistic, we can interpret congestion in the model as a bottleneck at the airport entrance, which is where we can expect to experience congestion on the actual road network. This also allows us to neglect non-duopoly traffic.

\subsection{Model Calibration}

We first need to calibrate our model using empirical data for the existing market equilibrium. For ease of exposition, the model described in Section 3.1 has a number of normalising assumptions, which need to be taken into account when using real data. The parameters derived below are presented in terms of the airport economy and have to be scaled appropriately to fit the model.

Weekly passenger numbers are used to determine the proportion of consumers using each airport in equilibrium and the trip frequency $\left(\alpha^{d}\right)$. We assume that one round-trip is made per passenger flight. Data on passenger numbers from the airports tell us that there are 17.5 million journeys per year with $89 \%$ of passengers using Zaventem and $11 \%$ Charleroi. The frequency of commuting trips $\left(\alpha^{w}\right)$ has been approximated using employment figures for the airports. We assume there are approximately 15,000 employees who work full time at the airports and commute from the city. It is clear from these data that not all inhabitants fly or work at the airports. Suitable scaling factors are therefore generated to take account in the model of the possible combinations of flying or not flying and working or not working at the two airports for city residents.

The uncongested travel times from the centre of Brussels to Zaventem and Charleroi are 16 and 39 minutes respectively. Congestion is assumed to increase travel time to Zaventem by $50 \%$ and have no effect on journeys to Charleroi. The bottleneck model is then used to calculate road capacity. Passengers may be considered to have a relatively high value of time (VOT) as there is a high penalty for being late for a flight. Here a value of $€ 20$ is adopted ${ }^{10}$.

Prices per passenger-flight are calculated from the lowest available advance internet weekend fare to Dublin with roughly the same departure and arrival times. The cost of one day long term parking is then added to this. Airport costs are determined by imposing that the airports break even and charge airlines and parking at $\operatorname{cost}^{11}$. These costs are divided into fixed and variable components. Labour costs are calculated by assuming an average annual gross salary of approximately $€ 70,000$ and work out to be roughly $35 \%$ of total costs. We then expect that in the calculated reference equilibrium, the average wage at Zaventem is likely to be higher given its size, location and quality.

Table A1-1 and Table A1-2 in Appendix 1 contain a summary of the fixed and variable data for the airport example. These data are scaled before being used in the model.

\footnotetext{
${ }^{10}$ This is in line with business VOT from UNITE (Nellthorp et al 2001).

${ }^{11}$ See, for example,Pels and Verhoef 2004, Zhang and Zhang 1997 for a discussion of airport pricing.
} 
Assigning a monetary value to utility of consumption $(h)$ and disutility of labour $(\beta)$ is not straightforward. Since, passenger-flight prices and congestion costs are higher for consumers using Zaventem in preference to Charleroi, we assume that this difference in cost is compensated for by $h$. In addition $h$ contains a premium for the perceived quality of the product at Zaventem (e.g. frequency of service). For $\beta$, we use the difference in wage plus travel costs between the two airports, which indicates that residents have slightly less inclination to work at Charleroi. Finally, we neglect the cost of road infrastructure and any government levies or head taxes. These have no impact on the market equilibrium but affect welfare.

Since we have price, wage and market share information, which are the model outputs, as well as the input data (costs, utilities and transport parameters), we can calibrate the model to obtain $\mu^{w}$ and $\mu^{d 12}$. In this case $\mu^{w}=2.8$ and $\mu^{d}=4.6$ so that the city inhabitants have a stronger preference for the airport they fly from than their work location ${ }^{13}$. The model input parameters and data for the existing market equilibrium can be found in Appendix 1.

\subsection{Results for policy scenarios}

The model results for the reference case are shown in Table 2 below. In addition we look at the effect of three policy scenarios: a 50\% transport infrastructure capacity extension to Zaventem, a differentiated toll and $10 \%$ government subsidy per passenger for Charleroi.

The results for the reference case indicate that airlines at Zaventem can charge a high price for flights relative to Charleroi because of the high quality (utility of consumption, $h$ ) of this airport. It is only consumers' relatively strong preference for departure location, $\mu^{d}$, which prevents Zaventem from capturing an even larger market share. Clearly its profits are considerably higher than Charleroi.

The first policy scenario we consider is a $50 \%$ increase in road capacity to Zaventem. This could also be interpreted as better airport access to parking.

Recall that only price minus wage can be calculated for each airport. Hence, the wage for Charleroi remains unchanged because this is held fixed in the numerical model. The changes in prices, wages and market share after the capacity expansion are quite small. The main reason for this is that in the model we have fixed demand, which is a small proportion of the total population (only approximately $5 \%$ of residents use the airport each week). So, additional capacity does not attract new customers but only existing customers away from Charleroi. The parameter $\mu^{d}$ is also a factor. Thus the reduction in

\footnotetext{
${ }^{12}$ This is done by substituting the data from Table A1-1 and Table A1-2 into equations (6), (7) and (13). Although $\mu^{d}+\mu^{w}$ can be calculated quite easily, the value for each parameter is obtained by trial and error to get a best fit to the data.

${ }^{13}$ These correspond to scaled values of $\mu^{d}=\mu^{w}=0.2$. The values strongly depend on the other model parameters: we can reverse the strength of preferences for working or shopping by adjusting the input parameters appropriately.
} 
travel costs of roughly $€ 2$ per trip makes Zaventem more attractive to potential passengers. The airport can slightly increase its price and reduce the wage it offers because both customers and employees have smaller travel costs but the changes are small as reducing prices attracts more customers, increasing congestion. Note that, in line with our results from Section 4.2, the price difference and difference in profits between Zaventem and Charleroi increase as road capacity increases and the wage difference decreases. The increase in the difference in profits is equivalent to a total gain of $€ 3$ million per year.

Welfare increases compared with the reference case because consumers experience reduced travel costs and Zaventem makes greater profits, which are returned to the consumer in our economy. The welfare gain of $€ 0.10$ per inhabitant over the economy of one week we consider in the model, corresponds to an annual total welfare gain of $€ 4$ million. It is however a gross gain and does not take account of the cost of building this additional infrastructure. The capital cost of extending a $10 \mathrm{~km}$ section of motorway, which has three lanes in each direction, by $50 \%$ can be estimated at $€ 30$ million (Quinet and Vickerman, p132, 2004). Maintenance costs over the lifetime can be expected to double this cost. This results in an annual cost of approximately $€ 6$ million, which is a similar order of magnitude to the annual welfare gain from implementing this policy.

\begin{tabular}{|c|c|c|c|c|c|c|c|c|}
\hline \multirow{2}{*}{ Case } & \multirow{2}{*}{ Airport } & Price & Wage & $\begin{array}{l}\text { Market } \\
\text { share }\end{array}$ & Gross profit & $\begin{array}{l}\text { Total } \\
\text { travel } \\
\text { cost }^{\#}\end{array}$ & $\begin{array}{c}\text { Change } \\
\text { in no } \\
\text { of road } \\
\text { users }\end{array}$ & $\Delta$ welfare \\
\hline & & $€ /$ trip & $\begin{array}{c}€ \\
\text { /hour }\end{array}$ & & $\begin{array}{c}€ / \\
\text { inhabitant/week }\end{array}$ & $€ /$ trip & /week & $\begin{array}{c}€ / \\
\text { inhabitant/ } \\
\text { week }\end{array}$ \\
\hline \multirow{2}{*}{ Reference } & Zaventem & 179.94 & 39.59 & 0.859 & 2.675 & 15.84 & & \multirow{2}{*}{0} \\
\hline & Charleroi & 95.75 & 37.22 & 0.141 & 0.066 & 26.00 & & \\
\hline \multirow{2}{*}{$\begin{array}{c}50 \% \text { capacity } \\
\text { extension } \\
\text { Zaventem }\end{array}$} & Zaventem & 181.27 & 39.53 & 0.866 & 2.752 & 14.14 & 2615 & \multirow{2}{*}{0.097} \\
\hline & Charleroi & 95.67 & 37.22 & 0.134 & 0.062 & 26.00 & & \\
\hline \multirow{2}{*}{$\begin{array}{l}\text { Differentiated } \\
\text { toll Zaventem }\end{array}$} & Zaventem & 179.63 & 39.72 & 0.865 & 2.673 & 13.27 & 1979 & \multirow{2}{*}{0.132} \\
\hline & Charleroi & 95.69 & 37.22 & 0.135 & 0.063 & 26.00 & & \\
\hline \multirow{2}{*}{$\begin{array}{c}10 \% \text { subsidy } \\
\text { per passenger } \\
\text { Charleroi }\end{array}$} & Zaventem & 177.66 & 39.47 & 0.855 & 2.583 & 15.81 & & \multirow{2}{*}{-0.011} \\
\hline & Charleroi & 93.28 & 37.22 & 0.145 & 0.068 & 26.00 & 1685 & \\
\hline
\end{tabular}

\# Excluding tolls

Table 2 Results for policy scenarios

The second policy option is to impose perfect time-differentiated tolling so that some consumers leave home earlier or later and queuing is eliminated. 
Again, changes in the price-wage equilibrium are very small compared with the reference case; as explained earlier this is due to the particular set-up of the two airport economy. Travel costs are also relatively small compared with other costs in the model. These depend on the value of time, which could probably be higher for passengers on their way to the airport. The route to Charleroi is not tolled as there is no congestion. The average toll for Zaventem reflects the queuing costs and the total toll revenue is a social benefit, increasing welfare. The elimination of queuing attracts more customers to Zaventem but the airport is forced to lower its price and increase its wage to maintain this market share because of the tolls, which are in total $€ 3.20$ per trip. The difference in profits between the two airports actually increases, while the profits themselves decrease. These changes also represent a benefit to the consumer and welfare is larger both than in the reference case and when road capacity is increased. The cost of implementing the tolling scheme has not, however, been included in the calculation.

One possible policy that would be attractive to politicians is to subsidise the smaller airport directly so that its marginal costs are reduced. We examine the effect of a $10 \%$ subsidy.

The marginal cost subsidy allows Charleroi to reduce its price quite significantly and increase its market share. Again, the size of the swing is governed by $\mu^{d}$. Zaventem is forced to reduce its prices to compete and suffers a reduction in profits. The subsidy increases the difference in marginal costs and, as determined in Section 4.1, this in fact leads to an increase in the difference in price between the two airports but a reduction in difference in wages, profits and market share. The cost of implementing this policy has been taken into account in the welfare calculation, resulting in a welfare loss compared to the reference case. The cost of the subsidy, assuming the marginal cost of public funds is equal to one is approximately $€ 400,000$ per year. This could be considered by some as a worthwhile investment to maintain employment at Charleroi.

\section{CONCLUSIONS}

In this paper we have presented a general equilibrium asymmetric model of imperfect competition with congestion. We have examined the duopoly model in detail and analysed the effects of firm quality, marginal costs and travel time differences on the difference in profits, prices and market share between the two firms. These theoretical findings are in line with the literature on airport choice, interpreting quality as flight frequency, and are illustrated in the numerical application to the competition between two airports. The calibration of the model to congested, nearby Zaventem and to the distant Charleroi airport data in Belgium has shown that there is a high premium placed on the quality of Zaventem airport and that consumers have quite strong preferences for where they fly from. We tested infrastructure policies, road pricing policies and subsidies for the distant. The results show only small changes from the reference equilibrium as our policies can only affect current users of the airports, who are only a small proportion of the overall population base. However, changes in profit and welfare are significant, making the policies more or less attractive to different groups. 
The model clearly has a number of limitations, which it would be interesting to explore in the future. We do not consider heterogeneous users, such as business and leisure travellers with different values of time. Further, no account is taken of different access modes to the airports or non-airport users.

The same proposed framework could not only be used to analyse the impact of a new airport (beside Orly and Paris Charles de Gaulle, a third airport has been under discussion for Paris for more than a decade), but also to study the impact of closing an old airport. A similar study could be carried out for the construction of a new terminal in an existing airport or the expansion of an existing terminal. In this case, the port authority also has to decide which airline company will use which terminal (such a discussion has taken place in Minneapolis, for example, where Northwest is a key actor, and has some decision making power concerning the usage of the old and the new terminal by other competing companies). The quantitative approach used here could explain what the consequences of such policies are and back-up the regulator decisions. 


\section{REFERENCES}

Anderson, SP. de Palma, A and Thisse, JF (1992): Discrete Choice Theory of Product Differentiation. MIT Press.

Arnott, R; de Palma, A. and Lindsey, R (1993): A Structural Model of Peak Period Congestion - A bottleneck model with elastic demand. American Economic Review 83(1), 161-179.

Barrett, SD (2004): How do the demands for airport services differ between full-service carriers and low-cost carriers? Journal of Air Transport Management, 10, 33-40.

Basar, G and Bhat, C (2004): A parameterised consideration set model for airport choice: an application to the San Francisco Bay Area. Transportation Research Part B, 38, 889-904.

Braess, D (1969): On a paradox of traffic planning. Unternehmensforschung 12, 258268.

Brueckner, J. (2002): Airport congestion when carriers have market power. American Economic Review, 92, 1357-1375.

de Palma, A and Leruth, L (1989): Congestion and game in capacity: A duopoly analysis in the presence of network externalities. Annales d'Economie et de Statistique, 15/16, 389-407.

de Palma, A and Lindsey, R (2000): Private toll roads: Competition under various ownership regimes. The Annals of Regional Science, 34, 13-35.

de Palma, A; Dunkerley, F and Proost, S (2004): Imperfect competition in a city with asymmetric subcentres. In Spatial Evolution and Modelling, Nijkamp, P and Reggiani, A (eds), Edward Elgar, in press.

de Palma, A; Dunkerley, F and Proost, S (2005): Trip Chaining - Who wins, who loses? Proceedings of ERSA Congress, Amsterdam August 2005.

de Palma, A. and Proost S (2005): Imperfect competition and congestion in the city. Journal of Urban Economics, forthcoming.

Fischer,T and Kamerschen, DR (2003): Price-cost margins in the US airline industry using a conjectural variational approach. Journal of Transport Economics and Policy, 37, 227-259.

Franke, M (2004): Competition between network carriers and low cost carriers - retreat battle or breakthrough to a new level of efficiency? Journal of Air Transport

Management, 10, 15-21.

Fujita, M and Thisse, J-F (2002): Economics of agglomeration-cities, industrial local and regional growth. CUP, Cambridge, 465p.

Hess, S and Polak, JW (2005): Mixed logit modelling of airport choice in multi-airport regions. Journal of Air Transport Management, 11, 59-68. 
Ivaldi, M. and Vibes, C (2004): Intermodal and intramodal competition in the long-haul passenger transport market. Manuscript, Université des Sciences Sociales de Toulouse.

Lambertini, L (1997): Optimal fiscal regime in a spatial duopoly. Journal of Urban Economics, 41, 407-420.

Nellthorp, J; Sansom, T; Bickel, P; Doll, C and Lindberg G (2001): Valuation Conventions for UNITE. UNITE Deliverable 5, Annex 3, ITS, England.

Pels, P, Nijkamp, P and Rietveld, P (2003): Access to and competition between airports: a case study for the San Francisco Bay area. Transportation research Part A, 37, 71-83.

Pels, E and Rietveld, P (2004): Airline pricing behaviour in the London-Paris market. Journal of Air Transport Management, 10, 279-283.

Pels, E and Verhoef, ET (2004): The economics of airport congestion pricing. Journal of Urban Economics, 48, 29-45.

Quinet, E and Vickerman, R (2004): Principles of Transport Economics. Edward Elgar, $385 p$.

Scotchmer, S (1985): Profit-maximising clubs. Journal of Public Economics, 27, 25-45.

Van Dender, K (2005): Duopoly prices under congested access. Journal of Regional Science, 45, 343-362.

Zhang, A and Zhang, Y (1997): Concession revenue and optimal airport pricing. Transportation Research Part E, 33, 287-296. 


\section{APPENDIX 1}

\begin{tabular}{|c|l|c|}
\hline $\mathrm{n}$ & No of airports & 2 \\
\hline $\mathrm{N}$ & No of consumers & $8,000,000$ \\
\hline$\mu^{d}$ & $\begin{array}{l}\text { Consumer heterogeneity for airport - } \\
\text { passenger }\end{array}$ & 4.6 \\
\hline$\mu^{w}$ & $\begin{array}{l}\text { Consumer heterogeneity for airport } \\
\text { employee }\end{array}$ & 2.8 \\
\hline$\alpha^{d}$ & No of trips per passenger flight & 0.13 \\
\hline$\alpha^{w}$ & No of trips per hour of labour & 5 \\
\hline$\delta$ & $\begin{array}{l}\text { Scaled value of time parameter for } \\
\text { congestion costs (€/hour) }\end{array}$ & 0 \\
\hline$\beta_{0}$ & $\begin{array}{l}\text { Disutility of labour for non-airport } \\
\text { employment }\end{array}$ \\
\hline
\end{tabular}

Table A1-1 Fixed model inputs

\begin{tabular}{|c|c|c|c|}
\hline Model inputs & & Zaventem & Charleroi \\
\hline $\mathrm{h}$ & $\begin{array}{c}\text { Airport quality } \\
(€ / \text { passenger flight) }\end{array}$ & 82 & 0 \\
\hline$\beta$ & $\begin{array}{l}\text { Disutility of labour } \\
(€ / \text { hour })\end{array}$ & 0 & 1.3 \\
\hline$t^{0}$ & $\begin{array}{c}\text { Return trip } \\
\text { uncongested travel } \\
\text { time (hours) }\end{array}$ & 0.53 & 1.3 \\
\hline $\mathrm{S}$ & $\begin{array}{l}\text { Road capacity } \\
\text { (vehicle/week) }\end{array}$ & 352,900 & - \\
\hline $\mathrm{c}$ & $\begin{array}{c}\text { Variable costs } \\
(€ / \text { passenger flight })\end{array}$ & 45 & 25 \\
\hline $\mathrm{F}$ & $\begin{array}{l}\text { Fixed costs } \\
(€ / \text { week })\end{array}$ & $22,385,720$ & $1,541,440$ \\
\hline Market data & & Zaventem & Charleroi \\
\hline price $(p)$ & (€/passenger flight) & 180.5 & 96.3 \\
\hline wage (w) & $(€ /$ hour $)$ & 37.2 & 37.2 \\
\hline market share & $\%$ city inhabitants & 89 & 11 \\
\hline
\end{tabular}

Table A1-2 Variable model inputs and existing market equilibrium 


\section{APPENDIX 2}

For the duopoly, with congestion, using the definitions $\Delta h=h_{2}-h_{1}, \Delta \beta=\beta_{2}-\beta_{1}$, $\Delta c=c_{2}-c_{1}$ and $\Delta t^{o}=t^{o}{ }_{2}-t^{o}{ }_{1}$, we can further define

$$
\Delta P^{d}=\frac{P_{2}^{d}}{s_{2}}-\frac{P_{1}^{d}}{s_{1}}=\frac{s_{1} \exp \left(\frac{X^{d}}{\mu^{d}}\right)-s_{2}}{s_{1} s_{2}\left(1+\exp \left(\frac{X^{d}}{\mu^{d}}\right)\right)},
$$

where $X^{d}=-\Delta p+\Delta h-\alpha^{d} \Delta t^{o}-\alpha^{d} \alpha \delta N \Delta P^{d}$. Equation (26), itself, has a unique fixed point $\Delta P^{d}$ for given $\Delta p$ and $\Delta w$. The Nash equilibrium first order conditions in prices and wages $p_{i}=\left(\mu^{d}+\mu^{w}\right)\left(1-P_{i}^{w}\right)^{-1}+w_{i}+c_{i}+\alpha^{h} t_{i}^{o}+\Lambda_{i}^{h} P_{i}^{w}+\delta N \hat{\alpha}^{2} s_{i}^{-1} P_{i}^{w}, i=1,2$ can then be rewritten as

$$
\Delta p=2\left(\mu^{d}+\mu^{w}\right) \sinh \left(\frac{X^{d}}{\mu^{d}}\right)+\Delta w+\Delta c+\alpha^{h} \Delta t^{0}+\alpha \alpha^{h} \delta N \Delta P^{d}+\hat{\alpha}^{2} \delta N \Delta P^{d} .
$$

From market clearing we know that $P_{1}^{w}=P_{1}^{d}$ and, since $P_{1}^{w}=\left[1+\exp \left(X^{w} / \mu^{w}\right)\right]^{-1}$ and $P_{1}^{d}=\left[1+\exp \left(X^{d} / \mu^{d}\right)\right]^{-1}$, we find a relationship between price and wage difference given by

$$
X^{w} / \mu^{w}=X^{d} / \mu^{d}
$$

Further, using (19) we can write

$$
\Delta w=\frac{\mu^{w}}{\mu^{d}} X^{d}+\Delta \beta+\alpha^{w} \Delta t^{0}+\alpha^{w} \alpha \delta N \Delta P^{w} .
$$

Combining (27) and (29), and given that market clearing also implies $\Delta P^{w}=\Delta P^{d}$, leads to

$$
X^{d}=-2 \mu^{d} \sinh \left(\frac{X^{d}}{\mu^{d}}\right)-\left(\frac{\mu^{d}}{\mu^{d}+\mu^{w}}\right) 2 \hat{\alpha}^{2} \delta N \Delta P^{d}+\left(\frac{\mu^{d}}{\mu^{d}+\mu^{w}}\right) B,
$$

where $B \equiv\left[\Delta h-\Delta \beta-\Delta c-\hat{\alpha} \Delta t^{0}\right]$ and $\hat{\alpha} \equiv \alpha^{d}+\alpha^{w}+\alpha^{h}$. Hence we have to solve (26) for given $\Delta p$ and $\Delta w$ to get $\Delta P^{w}$. Then (30) is solved to obtain $\Delta p$ and this can be substituted in (29) with $\Delta P^{w}$ to get $\Delta w$. We can also perform the same analysis for $X^{w}=\Delta w-\Delta \beta-\alpha^{w} \Delta t^{0}-\alpha^{w} \alpha \delta N \Delta P^{w}$ to obtain

$$
X^{w}=-2 \mu^{w} \sinh \left(\frac{X^{w}}{\mu^{w}}\right)-\left(\frac{\mu^{w}}{\mu^{d}+\mu^{w}}\right) 2 \hat{\alpha}^{2} \delta N \Delta P^{w}+\left(\frac{\mu^{w}}{\mu^{d}+\mu^{w}}\right) B .
$$

The difference in profits, $\Delta \pi=\pi_{2}-\pi_{1}$, can be determined from profit equation $\pi_{i}\left[w_{i}\right]=\left(p_{i}\left[w_{i}\right]-w_{i}-c_{i}-\alpha^{h} t_{i}\right) N P_{i}^{w}\left[w_{i}\right]-\left(F_{i}+S_{i}\right), i=1,2$ and the Nash equilibrium first order condition such that 


$$
\Delta \pi=2 N\left(\mu^{d}+\mu^{w}\right) \sinh \left(\frac{X^{d}}{\mu^{d}}\right)+\delta N^{2} \hat{\alpha}^{2}\left[\frac{\left(P_{2}^{d}\right)^{2}}{s_{2}}-\frac{\left(P_{1}^{d}\right)^{2}}{s_{1}}\right]-\Delta(F+S),
$$

where $\Delta(F+S)=F_{2}+S_{2}-F_{1}-S_{1}$ represents the difference in fixed costs between the two firms.

\section{A2.1 No congestion}

When there is no congestion (30) simplifies to

$$
X^{d}=-2 \mu^{d} \sinh \left(\frac{X^{d}}{\mu^{d}}\right)+\left(\frac{\mu^{d}}{\mu^{d}+\mu^{w}}\right) B,
$$

where $X^{d}=-\Delta p+\Delta h-\alpha^{d} \Delta t^{o}$ Likewise the profit difference equation becomes

$$
\Delta \pi=2 N\left(\mu^{d}+\mu^{w}\right) \sinh \left(\frac{X^{d}}{\mu^{d}}\right)-\Delta(F+S) .
$$

Using (20) and, we can also rewrite (21) as

$$
\frac{\Delta \pi}{N}=B-\frac{\mu^{d}+\mu^{w}}{\mu^{d}} X^{d}-\frac{\Delta(F+S)}{N} .
$$

Substituting the expression for $X^{d}$ into (20) and differentiating leads to

$$
\begin{aligned}
& \frac{\partial \Delta p}{\partial h}=1-\left(\frac{\mu^{d}}{\mu^{d}+\mu^{w}}\right)\left[1+2 \cosh \left(\frac{X^{d}}{\mu^{d}}\right)\right]^{-1}>0 \\
& \frac{\partial \Delta p}{\partial \beta}=\frac{\partial \Delta p}{\partial c}=\left(\frac{\mu^{d}}{\mu^{d}+\mu^{w}}\right)\left[1+2 \cosh \left(\frac{X^{d}}{\mu^{d}}\right)\right]^{-1}>0 \\
& \frac{\partial \Delta p}{\partial t^{o}}=\left[\hat{\alpha}\left(\frac{\mu^{d}}{\mu^{d}+\mu^{w}}\right)\left[1+2 \cosh \left(\frac{X^{d}}{\mu^{d}}\right)\right]^{-1}-\alpha^{d}\right]
\end{aligned}
$$

Similarly, using the equivalent expressions for $X^{w}$, we can derive

$$
\begin{aligned}
& \frac{\partial \Delta w}{\partial h}=\left(\frac{\mu^{w}}{\mu^{d}+\mu^{w}}\right)\left[1+2 \cosh \left(\frac{X^{w}}{\mu^{w}}\right)\right]^{-1}>0 \\
& \frac{\partial \Delta w}{\partial c}=-\left(\frac{\mu^{w}}{\mu^{d}+\mu^{w}}\right)\left[1+2 \cosh \left(\frac{X^{w}}{\mu^{w}}\right)\right]^{-1}<0 \\
& \frac{\partial \Delta w}{\partial \beta}=1-\left(\frac{\mu^{w}}{\mu^{d}+\mu^{w}}\right)\left[1+2 \cosh \left(\frac{X^{w}}{\mu^{w}}\right)\right]^{-1}>0 \\
& \frac{\partial \Delta w}{\partial t^{o}}=-\left[\hat{\alpha}\left(\frac{\mu^{w}}{\mu^{d}+\mu^{w}}\right)\left[1+2 \cosh \left(\frac{X^{w}}{\mu^{w}}\right)\right]^{-1}-\alpha^{w}\right]
\end{aligned}
$$


Finally, differentiating (20), the corresponding expression for $X^{w}$ and (35), we obtain

$$
\frac{1}{N} \frac{\partial \Delta \pi}{\partial B}=1-\left(1+2 \cosh \left(\frac{X^{d}}{\mu^{d}}\right)\right)^{-1}>0
$$

It can also easily be shown that $\Delta \pi$ is an increasing function of $\Delta h$ but a decreasing function of $\Delta \beta, \Delta c$ and $\Delta t^{\circ}$.

The strength of consumer preferences also play a role in the characteristics of the Nash equilibrium. Differentiating (20) and $X^{d}=-\Delta p+\Delta h-\alpha^{d} \Delta t^{o}$ leads to

$$
\begin{aligned}
& -\frac{\partial X^{d}}{\partial \mu^{d}}=\frac{\partial \Delta p}{\partial \mu^{d}}=-\left[1+2 \cosh \left(\frac{X^{d}}{\mu^{d}}\right)\right]^{-1}\left[2\left(\frac{X^{d}}{\mu^{d}}\right) \cosh \left(\frac{X^{d}}{\mu^{d}}\right)-2 \sinh \left(\frac{X^{d}}{\mu^{d}}\right)+\frac{B \mu^{w}}{\left(\mu^{d}+\mu^{w}\right)^{2}}\right] \\
& -\frac{\partial X^{d}}{\partial \mu^{w}}=\frac{\partial \Delta p}{\partial \mu^{w}}=\left[1+2 \cosh \left(\frac{X^{d}}{\mu^{d}}\right)\right] \frac{B \mu^{d}}{\left(\mu^{d}+\mu^{w}\right)^{2}}>0 \\
& \frac{\partial X^{w}}{\partial \mu^{w}}=\frac{\partial \Delta w}{\partial \mu^{w}}=\left[1+2 \cosh \left(\frac{X^{w}}{\mu^{w}}\right)\right]^{-1}\left[2\left(\frac{X^{w}}{\mu^{w}}\right) \cosh \left(\frac{X^{w}}{\mu^{w}}\right)-2 \sinh \left(\frac{X^{w}}{\mu^{w}}\right)+\frac{B \mu^{d}}{\left(\mu^{d}+\mu^{w}\right)^{2}}\right] \\
& \frac{\partial X^{w}}{\partial \mu^{d}}=\frac{\partial \Delta w}{\partial \mu^{d}}=-\left[1+2 \cosh \left(\frac{X^{w}}{\mu^{w}}\right)\right] \frac{B \mu^{w}}{\left(\mu^{d}+\mu^{w}\right)^{2}}<0
\end{aligned}
$$

Further, differentiating (21) we obtain

$$
\frac{\partial \Delta \pi}{\partial \mu^{d}}=\frac{\partial \Delta \pi}{\partial \mu^{w}}=2 N\left[1+2 \cosh \left(\frac{X^{d}}{\mu^{d}}\right)\right]^{-1}\left[2 \cosh \left(\frac{X^{d}}{\mu^{d}}\right)\left[\sinh \left(\frac{X^{d}}{\mu^{d}}\right)-\frac{B}{\mu^{d}+\mu^{w}}\right]+\sinh \left(\frac{X^{d}}{\mu^{d}}\right)\right]
$$

And we also find

$$
\frac{\partial\left(P_{2}^{d}-P_{1}^{d}\right)}{\partial \mu^{d}}=\frac{\partial\left(P_{2}^{d}-P_{1}^{d}\right)}{\partial \mu^{w}}=\frac{2}{\mu^{d}} \exp \left(\frac{X^{d}}{\mu^{d}}\right)\left(1+\exp \left(\frac{X^{d}}{\mu^{d}}\right)\right)^{-2}\left[\frac{\partial X^{d}}{\partial \mu^{d}}-\frac{X^{d}}{\mu^{d}}\right]
$$

Conditions could be derived for which price, wage, profit and market share differences will increase with the consumer heterogeneity parameters. These will clearly depend on $B, \mu^{d}$ and $\mu^{w}$.

\section{A2.2 Congestion with identical capacities}

When there is congestion but road capacity is the same for both firms, then (26) can be expressed as

$$
\Delta P^{d}=\left(\exp \left(\frac{X^{d}}{\mu^{d}}\right)-1\right) / s\left(1+\exp \left(\frac{X^{d}}{\mu^{d}}\right)\right)
$$


While the implicit price equations, (30) and (31) remain unchanged, the profit difference equation becomes

$$
\frac{\Delta \pi}{N}=B-\frac{\mu^{d}+\mu^{w}}{\mu^{d}} X^{d}-\delta N \hat{\alpha}^{2} \Delta P^{d}-\frac{\Delta(F+S)}{N} .
$$

Implicit differentiation of (30) leads to

$$
\frac{\partial X^{d}}{\partial s}=\left(\frac{\mu^{d}}{\mu^{d}+\mu^{w}}\right) \frac{2 \hat{\alpha}^{2} \delta N}{K s} \Delta P^{d},
$$

where $K=1+2 \cosh \left(\frac{X^{d}}{\mu^{d}}\right)+\frac{2 M}{s}$ and $M=\frac{2 \hat{\alpha}^{2} \delta N}{\left(\mu^{d}+\mu^{w}\right)} \exp \left(\frac{X^{d}}{\mu^{d}}\right)\left[1+\exp \left(\frac{X^{d}}{\mu^{d}}\right)\right]^{-2}$.Both

$K$ and $M$ are positive for all $X^{d}$. However, the derivative (41) is positive only for $X^{d}>0^{14}$ since $\Delta P^{d}$ is an increasing function of $X^{d}$ with $\Delta P^{d}=0$ (i.e. $P_{1}^{d}=P_{2}^{d}=1 / 2$ ) when $X^{d}=0$. Hence (41) has a minimum at $X^{d}=0$. Note, from (19), $K$ can also be expressed in terms of $X^{w} / \mu^{w}$ and moreover $\frac{\partial X^{w}}{\partial s}=\frac{\mu^{w}}{\mu^{d}} \frac{\partial X^{d}}{\partial s}$.

Differentiating (39) gives us

$$
\begin{aligned}
\frac{\partial \Delta P^{d}}{\partial s} & =-\frac{\Delta P^{d}}{s}+\frac{2}{s \mu^{d}} \exp \left(\frac{X^{d}}{\mu^{d}}\right)\left[1+\exp \left(\frac{X^{d}}{\mu^{d}}\right)\right]^{-2} \frac{\partial X^{d}}{\partial s}, \\
& =-\frac{\Delta P^{d}}{K s}\left[1+2 \cosh \left(\frac{X^{d}}{\mu^{d}}\right)\right]
\end{aligned}
$$

using (41). The above derivative is negative for $X^{d}>0$ but the difference in market share $\left(P_{2}^{d}-P_{1}^{d}\right)$ actually increases with capacity (decreases with congestion). Next taking the derivative of (24) and substituting from (41) and (42) yields the result

$$
\frac{\partial \Delta \pi}{\partial s}=\frac{\hat{\alpha}^{2} \delta N^{2}}{K s} \Delta P^{d}\left[2 \cosh \left(\frac{X^{d}}{\mu^{d}}\right)-1\right] .
$$

Hence the difference in profits increases with road capacity for $X^{d}>0$. In fact $\Delta \pi$ is minimised at $X^{d}=0\left(\Delta P^{d}=0\right)$.

Finally, differentiating $X^{d}=-\Delta p+\Delta h-\alpha^{d} \Delta t^{o}-\alpha^{d} \alpha \delta N \Delta P^{d}$ and again using (41) and (42) we obtain the result

$$
\frac{\partial \Delta p}{\partial s}=\frac{\alpha^{d} \alpha \delta N}{L s} \Delta P^{d}\left[1-\frac{2 \mu^{d}}{\mu^{d}+\mu^{w}} \frac{\hat{\alpha}}{\alpha^{d}}+2 \cosh \left(\frac{X^{d}}{\mu^{d}}\right)\right] .
$$

${ }^{14}$ Note (19) implies $X^{w}>0$. 
This implies that, for $X^{d}>0, \Delta p$ increases with road capacity when $\frac{3}{2} \frac{\alpha^{d}}{\hat{\alpha}}>\left(\frac{\mu^{d}}{\mu^{d}+\mu^{w}}\right)$ and decreases otherwise. The conditions are reversed for $X^{d}<0$. The corresponding result for the wage difference can be written

$$
\frac{\partial \Delta w}{\partial s}=-\frac{\alpha^{d} \alpha \delta N}{L s} \Delta P^{w}\left[1-\frac{2 \mu^{w}}{\mu^{d}+\mu^{w}} \frac{\hat{\alpha}}{\alpha^{w}}+2 \cosh \left(\frac{X^{w}}{\mu^{w}}\right)\right] .
$$

Hence, for $X^{d}>0, \Delta w$ increases with road capacity when $\frac{3}{2} \frac{\alpha^{w}}{\hat{\alpha}}<\left(\frac{\mu^{w}}{\mu^{d}+\mu^{w}}\right)$ and decreases otherwise. The conditions are reversed for $X^{d}<0$. Thus when the price difference increases in capacity, the wage difference generally decreases, depending on the trip frequency and consumer heterogeneity parameters. This is exactly the case when these parameters are identical for the two firms.

\section{A2.3 Congestion $s_{1} \neq s_{2}$}

Firstly considering the effect of changes in congestion levels, differentiation of (30) leads to

$$
\frac{\partial X^{d}}{\partial s_{1}}=-\left(\frac{\mu^{d}}{\mu^{d}+\mu^{w}}\right) \frac{2 \hat{\alpha}^{2} \delta N}{L s_{1}^{2}}\left[1+\exp \left(\frac{X^{d}}{\mu^{d}}\right)\right]^{-1}
$$

and

$$
\frac{\partial X^{d}}{\partial s_{2}}=\left(\frac{\mu^{d}}{\mu^{d}+\mu^{w}}\right) \frac{2 \hat{\alpha}^{2} \delta N}{L s_{2}{ }^{2}} \exp \left(\frac{X^{d}}{\mu^{d}}\right)\left[1+\exp \left(\frac{X^{d}}{\mu^{d}}\right)\right]^{-1}
$$

where $L=1+2 \cosh \left(\frac{X^{d}}{\mu^{d}}\right)+M\left[\frac{1}{s_{1}}+\frac{1}{s_{2}}\right]$ is positive for all $X^{d}$. Hence $X^{d}$ is an increasing function of $s_{2}$ and a decreasing function of $s_{1}$. Furthermore $\Delta P^{d}$ is a strictly increasing function of $X^{d}$

$$
\frac{\partial \Delta P^{d}}{\partial X^{d}}=\frac{1}{\mu^{d}}\left(\frac{1}{s_{1}}+\frac{1}{s_{2}}\right) \exp \left(\frac{X^{d}}{\mu^{d}}\right)\left[1+\exp \left(\frac{X^{d}}{\mu^{d}}\right)\right]^{-2},
$$

with $\Delta P^{d}=\frac{1}{2}\left[\frac{1}{s_{1}}+\frac{1}{s_{2}}\right]$ iff $X^{d}=0$. Equivalent results also apply for $X^{w}$.We can further differentiate $X^{d}=-\Delta p+\Delta h-\alpha^{d} \Delta t^{o}-\alpha^{d} \alpha \delta N \Delta P^{d}$ and use (45) and (46) above to show that

$$
\frac{\partial \Delta p}{\partial s_{1}}=-\frac{\alpha^{d} \alpha \delta N}{L s_{1}^{2}}\left[1+\exp \left(\frac{X^{d}}{\mu^{d}}\right)\right]^{-1}\left[1-\frac{2 \mu^{d}}{\mu^{d}+\mu^{w}} \frac{\hat{\alpha}}{\alpha^{d}}+2 \cosh \left(\frac{X^{d}}{\mu^{d}}\right)\right]
$$

and 


$$
\frac{\partial \Delta p}{\partial s_{2}}=\frac{\alpha^{d} \alpha \delta N}{L s_{2}{ }^{2}} \exp \left(\frac{X^{d}}{\mu^{d}}\right)\left[1+\exp \left(\frac{X^{d}}{\mu^{d}}\right)\right]^{-1}\left[1-\frac{2 \mu^{d}}{\mu^{d}+\mu^{w}} \frac{\hat{\alpha}}{\alpha^{d}}+2 \cosh \left(\frac{X^{d}}{\mu^{d}}\right)\right]
$$

Equations (47) and (48) imply that, for $X^{d}>0$, if $\frac{3}{2} \frac{\alpha^{d}}{\hat{\alpha}}>\left(\frac{\mu^{d}}{\mu^{d}+\mu^{w}}\right)$ the price difference $\Delta p$ increases with $s_{2}$ and decreases with $s_{1}$, while the opposite holds if $\frac{3}{2} \frac{\alpha^{d}}{\hat{\alpha}}<\left(\frac{\mu^{d}}{\mu^{d}+\mu^{w}}\right)$. The corresponding results for the wage differences imply that, for $X^{d}>0$, if $\frac{3}{2} \frac{\alpha^{w}}{\hat{\alpha}}<\left(\frac{\mu^{w}}{\mu^{d}+\mu^{w}}\right) \Delta w$ increases with $s_{2}$ and decreases with $s_{1}$, while the opposite holds if $\frac{3}{2} \frac{\alpha^{w}}{\hat{\alpha}}>\left(\frac{\mu^{w}}{\mu^{d}+\mu^{w}}\right)$. In both cases, the conditions are reversed for $X^{d}<0$. Note that the inequalities are the same as for identical road capacities.

Now differentiating (32) yields

$$
\frac{\partial \Delta \pi}{\partial s_{1}}=-\frac{Q}{s_{1}^{2}}\left[2 \cosh \left(\frac{X^{d}}{\mu^{d}}\right)\left(1+2 \exp \left(\frac{X^{d}}{\mu^{d}}\right)+\right) M\left(\frac{\left(2 \exp \left(X^{d} / \mu^{d}\right)-1\right)}{s_{2}}+\frac{1}{s_{1}}\right)\right]
$$

and

$$
\frac{\partial \Delta \pi}{\partial s_{2}}=\frac{Q}{s_{2}{ }^{2}} \exp \left(\frac{X^{d}}{\mu^{d}}\right)\left[2 \cosh \left(\frac{X^{d}}{\mu^{d}}\right)\left(2+\exp \left(\frac{X^{d}}{\mu^{d}}\right)\right)+M\left(\frac{\left(2-\exp \left(X^{d} / \mu^{d}\right)\right)}{s_{1}}+\frac{\exp \left(X^{d} / \mu^{d}\right)}{s_{2}}\right)\right]
$$

where $Q=\frac{\hat{\alpha}^{2} \delta N^{2}}{L}\left[1+\exp \left(\frac{X^{d}}{\mu^{d}}\right)\right]^{-2}$ is always positive. Clearly $\Delta \pi$ is a decreasing function of $s_{1}$ and an increasing function of $s_{2}$ for $X^{d}>0$.

With regard to the comparative statics for price, wage and profit differences as a function of exogenous input parameters, it can be shown that the results found for the no congestion case generalise to the case with congestion. The conditions for $\Delta t^{o}$ are of course different but still depend on the trip frequency and consumer heterogeneity.

Substituting for $X^{d}=-\Delta p+\Delta h-\alpha^{d} \Delta t^{o}-\alpha^{d} \alpha \delta N \Delta P^{d}$ in (30), differentiating with respect to the exogenous parameters and using (46) leads to the following set of results: 


$$
\begin{aligned}
& \frac{\partial \Delta p}{\partial \Delta h}=\frac{1}{L}\left[\frac{\mu^{w}}{\mu^{d}+\mu^{w}}+2 \cosh \left(\frac{X^{d}}{\mu^{d}}\right)+\frac{M}{2}\left(\frac{1}{s_{1}}+\frac{1}{s_{2}}\right)\right]>0 \\
& \frac{\partial \Delta p}{\partial \Delta \beta}=\frac{\partial \Delta p}{\partial \Delta c}=\frac{1}{L}\left[\frac{\mu^{d}}{\mu^{d}+\mu^{w}}+\frac{M}{2}\left(\frac{1}{s_{1}}+\frac{1}{s_{2}}\right)\right]>0 \\
& \frac{\partial \Delta p}{\partial \Delta t^{o}}=\frac{1}{\alpha^{d} L}\left[\frac{\mu^{d}}{\mu^{d}+\mu^{w}} \frac{\hat{\alpha}}{\alpha^{d}}-1-2 \cosh \left(\frac{X^{d}}{\mu^{d}}\right)-M\left(1-\frac{\hat{\alpha}}{2 \alpha^{d}}\right)\left(\frac{1}{s_{1}}+\frac{1}{s_{2}}\right)\right]
\end{aligned}
$$

Similarly, using the equivalent expressions for $X^{w}$, we can derive

$$
\begin{aligned}
& \frac{\partial \Delta w}{\partial \Delta h}=\frac{1}{L}\left[\frac{\mu^{w}}{\mu^{d}+\mu^{w}}+\frac{M}{2}\left(\frac{1}{s_{1}}+\frac{1}{s_{2}}\right)\right]>0 \\
& \frac{\partial \Delta w}{\partial \Delta \beta}=\frac{1}{L}\left[\frac{\mu^{d}}{\mu^{d}+\mu^{w}}+2 \cosh \left(\frac{X^{w}}{\mu^{w}}\right)+\frac{M}{2}\left(\frac{1}{s_{1}}+\frac{1}{s_{2}}\right)\right] \\
& \frac{\partial \Delta w}{\partial \Delta c}=-\frac{1}{L}\left[\frac{\mu^{w}}{\mu^{d}+\mu^{w}}+\frac{M}{2}\left(\frac{1}{s_{1}}+\frac{1}{s_{2}}\right)\right]<0 \\
& \frac{\partial \Delta w}{\partial \Delta t^{o}}=\frac{1}{\alpha^{w} L}\left[1+2 \cosh \left(\frac{X^{d}}{\mu^{d}}\right)-\frac{\mu^{w}}{\mu^{d}+\mu^{w}} \frac{\hat{\alpha}}{\alpha^{w}}+M\left(1-\frac{\hat{\alpha}}{2 \alpha^{w}}\right)\left(\frac{1}{s_{1}}+\frac{1}{s_{2}}\right)\right]
\end{aligned}
$$

To determine the effect of the difference in rank parameter $\mathrm{B}$ on the relative profits of the two firms, we differentiate profit difference equation (32) to obtain

$$
\frac{1}{N} \frac{\partial \Delta \pi}{\partial B}=\frac{1}{L}\left[2 \cosh \left(\frac{X^{d}}{\mu^{d}}\right)+M\left(\frac{\exp \left(X^{d} / \mu^{d}\right)}{s_{2}}+\frac{1}{s_{1}}\right)\right],
$$

which is positive for all $X^{d}$. 
The Center for Economic Studies (CES) is the research division of the Department of Economics of the Katholieke Universiteit Leuven. The CES research department employs some 100 people. The division Energy, Transport \& Environment (ETE) currently consists of about 15 full time researchers. The general aim of ETE is to apply state of the art economic theory to current policy issues at the Flemish, Belgian and European level. An important asset of ETE is its extensive portfolio of numerical partial and general equilibrium models for the assessment of transport, energy and environmental policies.

\section{ETE WORKING PAPER SERIES 2005}

$N^{\circ} 2005-09$

$\mathrm{N}^{\circ} 2005-08$

N²005-07

N²005-06

N²005-05

N²005-04

N²005-03

N²005-02

N²005-01
Dunkerley F., de Palma A. and Proost S. (2005), Asymmetric Duopoly in Space - what policies work?

Rousseau S. (2005), The use of warnings when intended and measured emissions differ

Proost S., Van der Loo S., de Palma A., Lindsey R. (2005), A costbenefit analysis of tunnel investment and tolling alternatives in Antwerp

de Palma A., Lindsey R. and Proost S. (2005), Research challenges in modelling urban road pricing: an overview

Moons E., Rousseau S. (2005), Policy design and the optimal location of forests in Flanders

Mayeres I., Proost S. (2005), Towards better transport pricing and taxation in Belgium

Proost S., Sen A. (2005), URBAN Transport pricing reform with TWO levels of government

Moons E., Saveyn B., Proost S., Hermy M. (2005), Optimal location of new forests in a suburban area

Pepermans G., Willems B. (2005), The potential impact of crossownership in transmission: An application to the Belgian electricity market

\section{ETE WORKING PAPER SERIES 2004}

N²004-16

N²004-15
Franckx L, D’Amato A., Brose I. (2004), Multi Pollutant Yardstick Schemes as Environmental Policy Tools

Rousseau S., Proost S. (2004), The Relative Efficiency of Marketbased Environmental Policy Instruments with Imperfect Compliance 